to pay for the goods they consumed had fallen to half that of 1914 . In 1929, more than a quarter of US farm income came from exports, again now talked of as the salvation of the US farmer. But then, far from being a salvation, export dependence precipitated further disaster when the export market collapsed.

Overproduction is still a chronic problem. And if, now, imbalance of general trade has at least provided Europe and Japan with the US currency with which to purchase US goods (not the case in the 1920s), the potential customers' restraints on trade to protect their own farmers and the overpriced US dollar are at least equal barriers. It is difficult to see how overproduction of US farm commodities can create its own demand in these artificial circumstances.

There is nevertheless much that could be done to reform the US price support system. The administration is looking in the right place, if in the wrong spirit. Whatever its ambitions now, the administration will probably not be able to eliminate the system of price support, which has at least served well to smooth out the natural cycles of boom and bust. The chief mechanism is that of loans granted to farmers at harvest time against crops as collateral; if the farmer is unable to sell his crop at a price equal to or better than the loan price, he has the option of defaulting, in effect selling his crop to the government. This prevents a pricedepressing glut at harvest time and removes a minimal amount of overproduction from the market. But there is little justification for maintaining the expensive programmes that amount to all-out production incentives. Any rational farm policy must put a premium on greater efficiency rather than greater production. That is simply not the case now, when farmers find the best and, indeed, often the only avenue to increased income is expansion.

The present approach to agricultural research can only exacerbate these structural failings of the farm programmes. The emphasis on applied, production-oriented, short-term results brought about by the anachronistic formula-fund system of agricultural research can only encourage the overproduction mentality. By every estimate, US agricultural research is woefully undersupported, yielding a return on investment many times greater than the norm for other businesses. The absence of peer review in the award of most research grants ensures that special interests have a disproportionate say in the choice of research priorities, exacerbating the short-term view of many researchers in the land-grant college system.

Yet a greater investment in fundamental research, particularly plant molecular biology, could lead to substantial reductions of production costs, for example by reducing or eliminating the need for energy-intensive inputs such as pesticides and fertilizers. The $\$ 46$ million that Congress managed to appropriate this year for research is a sound first step, but far less than private corporations are spending in this field. Now, within the overall context of US farm policy, the time has come to acknowledge that agricultural research is too important to be left to the vagaries of share-thewealth formula funding, and more relevant to the long-term stability of the farm economy than the narrow pursuit of increased production that now passes for a research strategy.

\section{European initiatives}

\section{The European Science Foundation has had ten modest years. Now it needs to be more daring.}

THAT it is high time that something more was done about the organization of science in Europe is beyond dispute. What perplexes people is to know with some clarity what should be done. Lord Flowers, the first president of the European Science Foundation, canvassed one modest set of proposals at the tenth anniversary meeting of the foundation in Strasbourg last week. In a public lecture on "the first twenty years" ( a joke intended to encompass both the formal lifespan of the foundation and its gestation period), Flowers rightly claimed on behalf of the foundation a string of notable achievements in the past few decades, among which (just now) the most conspicuous is the plan for building a powerful source of synchrotron radiation in
Western Europe (see Nature 1 November, p.3 and 15 November, p. 189). Properly, however, Flowers boasted of the way in which the foundation has been asked by the Council of Europe to carry out a study of the ways in which the mobility of scientists in Europe might be increased and he urged that the British government's last-minute proposal at last month's European meeting in Paris, that there should be a European academy of some kind, should be taken more seriously than its half-baked character would otherwise ensure. Persuasively, he argued that an institution such as the European Science Foundation, which is essentially a forum in which European grant-making agencies can put their heads together over common problems, and think of solving some of them, must run the danger of losing touch with the individual researchers on whom its success must depend.

Nobody in Europe will quarrel with a word of this, at least so far as it goes. Lord Flowers, the chief architect of the foundation, is understandably wedded to the notion of organic growth in European collaboration. He and others were also at the outset convinced that the creation of a body such as the European Science Foundation beneath the umbrella of the European Communities would be disastrous, however large the annual budget. That decision was without question correct. Freedom from the Commission's tutelage has allowed the foundation to draw its membership from all over Europe, not simply from that part in which the European Commission's legal writ runs. More important, the foundation has not found itself in the invidious position of having to look for solutions to the short-term and often artificial problems that the Commission repeatedly singles out as urgent. If it had accepted the Commission's offer of financial support, the foundation would long since have found itself tackling the impossible task of hammering out, or even carrying out, a research programme to make European computers better than other people's, or to resolve the endless (and intrinsically political) conflict about the basis on which environmental regulations should be set. Instead, the foundation has been able to tackle the tasks at which its chance of success was reasonably good. The long-term goal is the encouragement of a sense of community within European science. With the passage of time, the argument seems to run, the scientific community will itself determine how a European scientific community should be organized.

If there were the whole of time to play with, such a policy would make good sense. But the successful pursuit of the ideal is possible only within an ideal environment. In Europe as it really is, the problems afflicting the scientific communities of at least half a dozen states are too urgent to be allowed to wait. When European research institutes such as the European Organization for Nuclear Research (CERN), rightly held out as successes for European collaboration, are themselves threatened by the possible defection of member states such as Britain, when plans for collaborating in other international research programmes (such as deep-sea drilling) are frustrated by the general shortage of funds and when it seems likely that important pieces of nationallybuilt scientific equipment will be wasted because their builders (the British research councils in particular) can no longer afford to use them properly, there is a strong European case for some more robust mechanism for mutual support in times of trouble. For its own sake, the European Science Foundation does not want to be hurried. But that may be too great a luxury to expect.

What, in these circumstances, might be done? The best chance is that the foundation may be able to move on from identifying barriers to mobility within Europe to becoming a monitor of what is happening within European science. There are housekeeping jobs to do, such as the compilation of the up-to-date register of who does what research, now done by some European governments, but always unsystematically. There is also the more contentious task to tackle of inducing among the European research councils (most of whom are members of the foundation) a sense that coordination of some kind would be desirable. Even a device as simple as trying to produce an annual report on European academic science would be a sensible starting point. But these are only beginnings. 